\title{
CLINICAL OUTCOMES AFTER TWO-STAGE BICRUCIATE KNEE LIGAMENT RECONSTRUCTION
}

\author{
RESULTADO CLÍNICO APÓS RECONSTRUÇÃO \\ LIGAMENTAR BICRUZADO DO JOELHO, EM DOIS TEMPOS
}

\author{
Mauro Mituso InAda ${ }^{1}$ (1), SÉrgio Rocha Piedade ${ }^{1}$ (i) \\ 1. Sports and Exercise Medicine Group, Department of Orthopedics, Rheumatology and Traumatology (DORT), SChool of Medical Sciences, University of Campinas-UNICAMP, \\ Campinas, SP, Brazil.
}

\section{ABSTRACT}

Objective: To correlate clinical and intraoperative findings with the postoperative evaluation of two-stage bicruciate knee ligament reconstruction. Methods: The study was conducted with 25 patients (20 men and 05 women) with mean age of 32.3 years, mean body mass index (BMI) of 26.2, and mean lesion duration of 18.3 months. The treatment consisted of an Inlay reconstruction of the posterior cruciate ligament (PCL) followed by the anterior cruciate ligament (ACL) reconstruction, at least 3 months after the first surgical procedure. Four patients required additional procedures: patellar tendon (02), medial collateral ligament (MCL) (02). Results: With an average follow-up of 24.8 months, $60 \%$ of the patients scored zero or + at the posterior drawer test, while $40 \%$ scored $++; 60 \%$ of patients were evaluated as good/excellent according to the Lysholm scale. Only one patient reached the pre-injury Tegner activity level. Injury duration had a negative influence on functional limitation, vitality, and mental health (SF-36). Conclusion: Although two-stage bicruciate knee ligament reconstruction improved knee stability and self-assessment, $96 \%$ of patients did not recover their pre-injury state. In the 36-item short form survey (SF-36), injury duration was inversely correlated with self-assessment of functional capacity, physical limitation, vitality, and mental health. Level of Evidence II, retrospective study.

Keywords: Posterior Cruciate Ligament. Knee Injuries. Ligaments. Patient Reported Outcomes Measures.

\section{RESUMO}

Objetivo: Correlacionar os achados clínicos e intraoperatórios com a avaliação pós-operatória da reconstrução ligamentar bicruzada do joelho em dois tempos. Métodos: 25 pacientes (20 homens e 05 mulheres), média de idade de 32,3 anos, IMC médio de 26,2, tempo médio da lesão de 18,3 meses. O tratamento foi iniciado com a reconstrução INLAY do LCP e, após o intervalo mínimo de 3 meses, foi realizada a reconstrução do LCA. Procedimentos adicionais em 04 pacientes - tendão patelar (02), LCM (02). Resultados: com seguimento médio de 24,8 meses, o teste de gaveta posterior foi classificado como zero ou + em $60 \%$ dos pacientes avaliados e $40 \%$ como $++.60 \%$ dos pacientes avaliados como bons / excelentes (Lysholm). Apenas um paciente atingiu o nível de atividade Tegner pré-lesão. A tempo da lesão influenciou negativamente os parâmetros de limitação do funcionamento físico dos aspectos físicos, vitalidade e saúde mental (SF-36). Conclusão: a reconstrução bicruzado do joelho, em dois tempos, melhorou a estabilidade do joelho e a avaliação subjetiva, mas 96\% dos pacientes não recuperaram o estado pré-lesão. O tempo de lesão apresentou correlação estatística inversa com a avaliação subjetiva da capacidade funcional, limitação dos aspectos físicos, vitalidade e saúde mental no escore S-36. Nível de Evidência II, Estudo retrospective.

Descritores: Ligamento Cruzado Posterior. Traumatismos do Joelho. Ligamentos. Medidas de Resultados Relatados pelo Paciente.

Citation: Inada MM, Piedade SR. Clinical outcomes after two-stage bicruciate knee ligament reconstruction. Acta Ortop Bras. [online]. 2021;29(1):7-11. Available from URL: http://www.scielo.br/aob.

\section{INTRODUCTION}

Bicruciate knee ligament injury, that it, lesions affecting both the posterior cruciate ligament (PCL) and the anterior cruciate ligament $(A C L)$ simultaneously, is one of the most severe knee joint injuries, occupying a chapter of its own in the universe of knee ligament lesions. ${ }^{1,2}$ Considering that, surgeons' knowledge about the complex anatomy and biomechanics of both ligaments, trauma history and mechanism, and patients' physical demand level plays a vital role in the decision-making process of this condition.

This complex knee ligament injury is a rare injury, mostly associated with high-energy traumas incurring or not in lesions of

All authors declare no potential conflict of interest related to this article.

The study was conducted at Exercise and Sports Medicine Group, Department of Orthopedics, Rheumatology and Traumatology

Correspondence: Sergio Rocha Piedade. Rua Severo Penteado 131, apto 01, Cambuí, Campinas, SP, Brazil, 13025050. piedade@unicamp.br 
other joints, structures, or organs. Meniscal and osteochondral injuries also commonly occur with other peripheral ligament lesions, worsening symptoms, instability, and joint degeneration. ${ }^{3}$ Boisgard et al. ${ }^{4}$ described four types of bicruciate knee ligament injury mechanisms: the first one concerns a simple plane femorotibial gaping around a perpendicular axis; the second occurs due to femorotibial translation; the third is a combination of simple gaping and knee translation; and the last is a combination of femorotibial gaping and translation, isolated or associated with rotational movements. ${ }^{5}$ However, the clinical practice may fail in identifying the mechanism of injury, especially in chronic cases, due to patients underreporting.

From a biomechanical perspective, knee bicruciate injuries affect stability and normal joint kinematics, causing significant clinical repercussions that interfere in individuals' quality of life. Given the complexity of this lesion, specialists indicate a surgical procedure.

Studies approaching the outcomes of bicruciate knee ligament reconstruction on quality of life, symptoms improvement, return to work and sports practice, as well as subjective and objective assessments of outcomes are still scarce on the literature, thus presenting a topic of substantial interest.

This study aims to correlate clinical and intraoperative data with postoperative evaluation obtained from the Lysholm knee scoring scale, Tegner activity score, and SF-36 questionnaire after two-stage bicruciate knee ligament reconstruction.

\section{MATERIALS AND METHODS}

This retrospective descriptive study analyzed thirty-one (31) patients who underwent two-stage bicruciate knee ligament reconstruction between 2002 and 2010 .

\section{Exclusion criteria}

Patients presenting bilateral lesion ( $n=1)$, intra-articular fracture of the lateral tibial plateau $(n=1)$, and tibial osteotomy $(n=2)$ were excluded from the study. Two patients were also lost to follow-up, totaling six excluded patients. Therefore, the study comprised 25 patients (Table 1 ).

Table 1. Patients' characteristics, affected knee, mechanism of injury, and associated injuries.

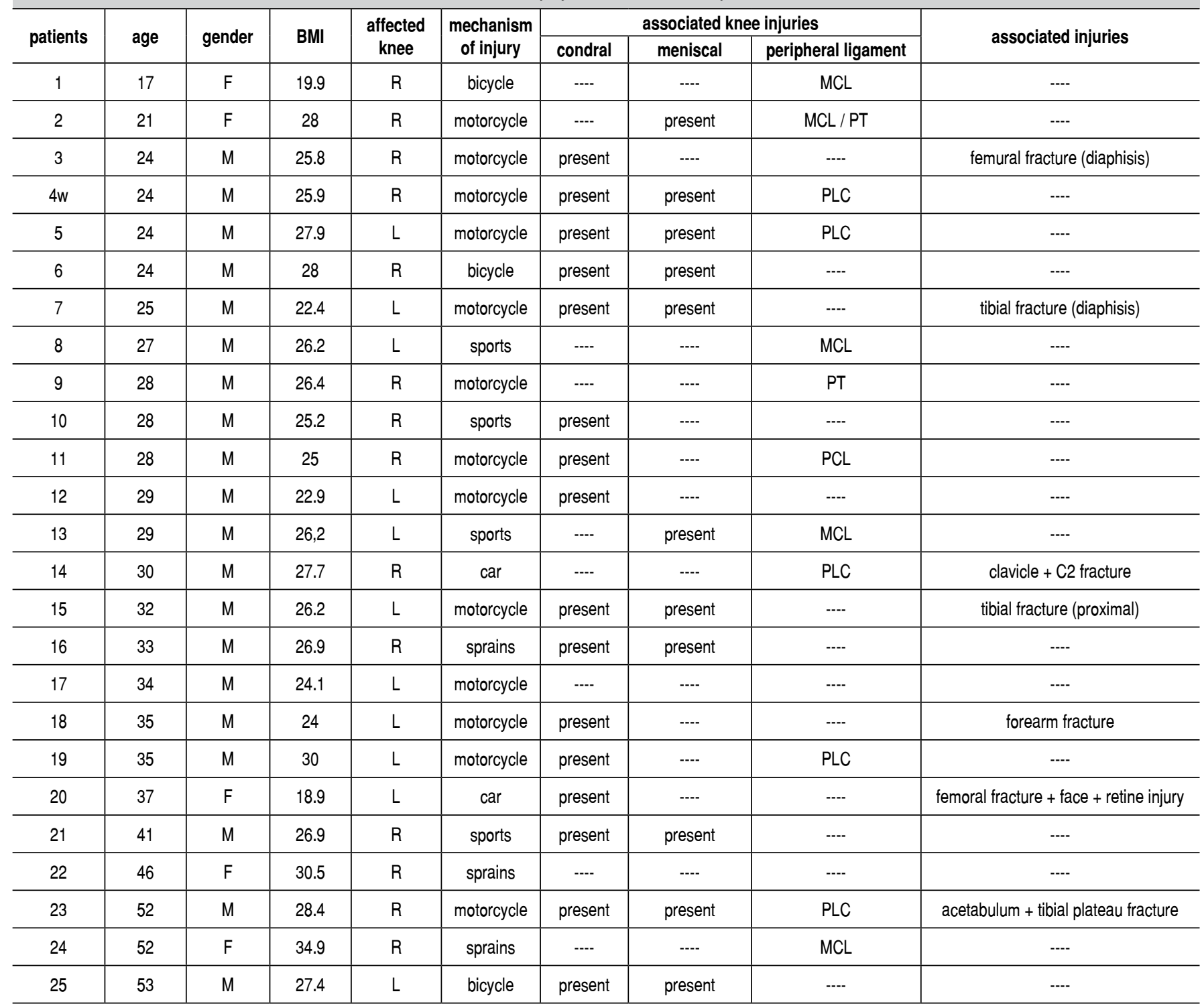




\section{Cases}

Twenty-five patients were reassessed (twenty men and five women). Among these, mean age was $32.3 \pm 9.81$ years $(17-53)$, mean body mass index (BMI) was $26.2 \pm 3.27$ (18.9-34.9), and 14 presented the right knee affected whereas 11 presented the left knee.

Regarding the mechanism of injury, car, motorcycle, and bicycle accidents were responsible for $72 \%$ of injuries, sports practices for $16 \%$, and falls or sprains for $12 \%$.

Average lesion duration was $18.28 \pm 29.63$ months $(1-120)$, so that all patients had chronic injuries.

\section{Surgical technique}

Patients' mean age at surgery was 29.4 years $(16-50)$. Inlay posterior cruciate ligament (PCL) reconstruction with a central third patellar tendon graft was one of the surgical techniques used. The graft was fixed in the femoral tunnel with a interference screw and in the tibial tunnel with cortical screw and washer (Figure 1). In the postoperative care, the knee remained extended in inguinalmalleolus splint for six weeks.

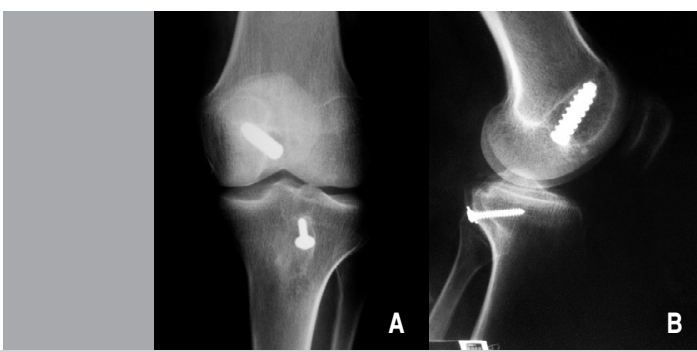

Figure 1. Postoperative radiographs of open Inlay PCL reconstruction: anteroposterior (A) and lateral $(B)$ view of the knee.

After at least 3 months from the first surgical procedure and observing an improvement in the range of motion, patients underwent anatomical outside-in arthroscopic anterior cruciate ligament (ACL) reconstruction using quadruple hamstring grafts and interference screws fixation in both the femur and tibia (Figure 2).

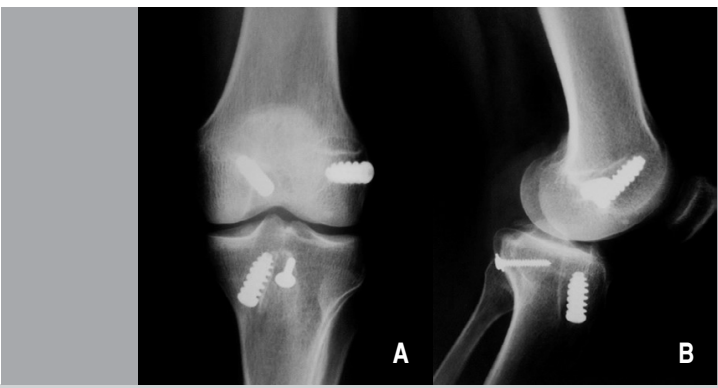

Figure 2. Postoperative radiographs of arthroscopic $A C L$ reconstruction: (A): anterior-posterior; and (B) lateral view of the knee.

Four patients with associated lesions in ligaments required additional surgery: two underwent patellar tendon reconstruction using contralateral semitendinosus-gracilis grafts, and two underwent medial collateral reconstruction using contralateral semitendinosus-gracilis grafts.

\section{Intraoperative findings}

Data on meniscal and chondral lesions (grade $\geq 2$ ) were obtained from medical records. These lesions were prevalent on the medial side of the knee (femoral condyle, medial tibial plateau), patellar surface. For being considered minor injuries, the reports only contained information on the presence or absence of cartilage damage, without areas measurement.

\section{Postoperative evaluation}

Mean postoperative follow-up was $24.8 \pm 20.63$ months $(9-92)$. Data regarding clinical and radiological assessment was collected, as well as on functional assessment according to the Lysholm scale, Tegner activity score, and the 36-item short form survey (SF-36). Thighs circumference was measured $14 \mathrm{~cm}$ above the upper end of the patella. All participants agreed to participate by providing informed consent, and the study was approved by the institution Ethics Committee (CEP no. 963/2010).

\section{Statistical analysis}

Statistical analyses were conducted on the Statistical Package for the Social Sciences (SPSS) 13.0. Numerical and categorical variables were tested using the Mann-Whitney, Spearman, and Wilcoxon tests, with significance level set at $p<0.05$.

Univariate and multivariate linear regression analyses were performed to identify variables influencing participants' quality of life and clinical assessment. In the absence of normality, dependent variables were transformed using stepwise selection. Statistical tests were conducted considering a $5 \%$ significance level.

\section{RESULTS}

After treatment completion, all 25 patients fully recovered the range of motion. In 10 patients (40\%), the difference in thighs circumference was greater than $2 \mathrm{~cm}$ when compared to postoperative evaluation.

According to the posterior drawer test, tibialis posterior drawer decreased by at least one level (+ or $0.5 \mathrm{~cm}$ ). Seven patients $(28 \%)$ presented a negative posterior drawer, eight patients (32\%) showed a $0.5-\mathrm{cm}$-residual posterior drawer $(+/+++)$, and ten patients $(40 \%)$ presented a $1-\mathrm{cm}$-residual posterior drawer $(++/+++)$, but none presented residual posterior drawer $\geq 1.5 \mathrm{~cm}(+++/+++)$ in the operated knee.

Sixteen patients presented chondral lesion (64\%), 11 presented meniscal lesion (44\%), and 12 associated ligament lesion (48\%). Clinical records contain intraoperative findings on chondral injury, but no measurements.

Regarding associated lesions in ligaments, two patients presented patellar tendon injuries (08\%), five presented medial collateral ligament injuries (20\%) and six patients posterolateral corner injuries (24\%) (Figure 3). Patellar tendon reconstruction was performed on two patients and medial collateral reconstruction on other two, but none of the six patients diagnosed with mild posterolateral corner injury was submitted to surgical reconstructions.

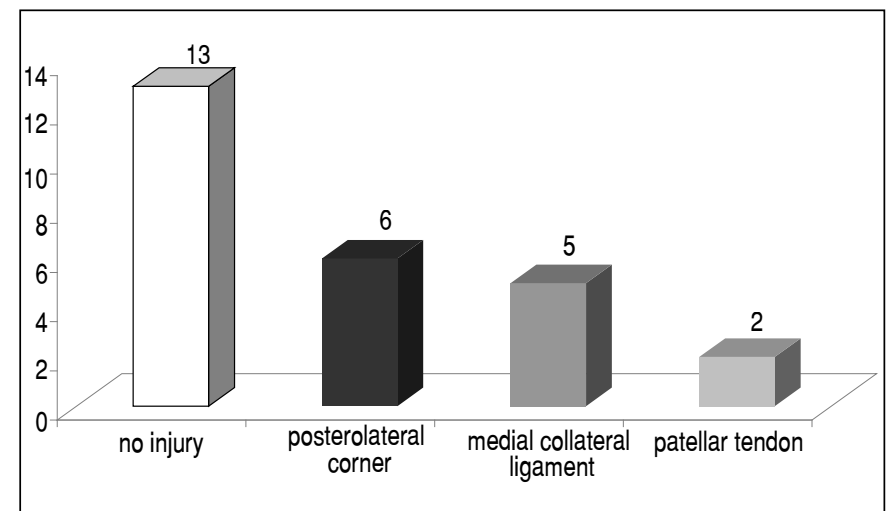

Figure 3. Distribution of associated ligament lesions in the 25 evaluated cases. 
We found no statistical difference among groups regarding age, $\mathrm{BMI}$, presence of associated chondral, meniscal, and ligament lesions, and residual posterior drawer.

According to the Lysholm score $(83.44 \pm 16.83)$, eight patients $(32 \%)$ presented excellent results, seven (28\%) presented good results, eight $(32 \%)$ regular, and two (8\%) poor results (Figure 4).

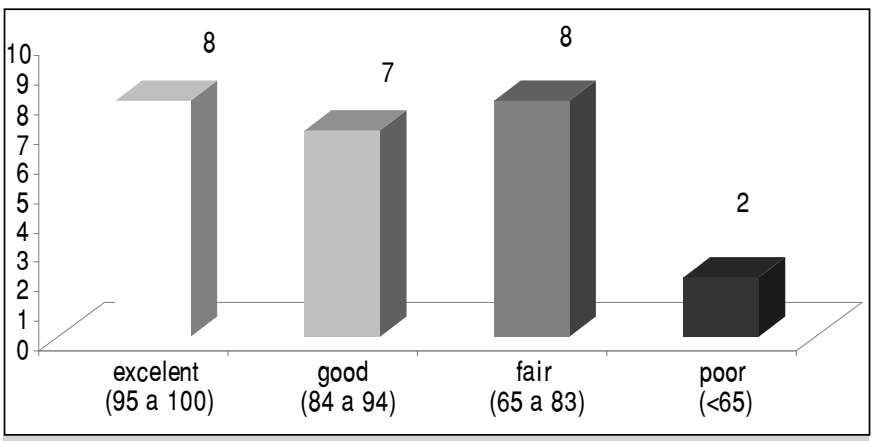

Figure 4. Distribution of Lysholm scores of the 25 evaluated cases.

According to the Tegner activity score, the postoperative physical activity level was lower than that reported before the injury (Table 2). However, such change was not statistically significant. Only one patient within our study sample achieved the pre-injury activity level $(p<0.001)$.

Table 2. Patients' distribution according to Tegner activity score levels (light, moderate, and high) and Postoperative Tegner deficit (mean values and standard deviation).

TEGNER (physical activity level)

\begin{tabular}{c|c|c|c|c}
\hline Condition & light (0 to 3) & $\begin{array}{c}\text { moderate } \\
\text { (4 to } 6)\end{array}$ & high (7 to 10) & $\begin{array}{c}\text { postoperative } \\
\text { Tegner deficit }\end{array}$ \\
\hline pre-injury & 7 & 13 & 5 & \multirow{2}{*}{$35.56 \pm 18.81$} \\
\hline postoperative & 16 & 7 & 2 & \\
\hline
\end{tabular}

We found a statistical correlation between the Lysholm scale and Tegner deficit, whereby the higher the Lysholm score, the smaller the physical activity decrease after bicruciate knee ligament reconstruction. Preoperative lesion duration was inversely correlated with physical functioning, physical limitation, vitality, and mental health (SF-36 questionnaire), indicating a negative impact on clinical outcomes. Table 3 shows SF-36 results.

Table 3. Mean, standard deviation, and range SF-36 scores for the 25 patients.

\begin{tabular}{c|c|c|c}
\hline SF-36 scores & mean values & SD & range \\
\hline physical functioning & 71 & \pm 21.2 & $(30-100)$ \\
\hline role functioning-physical & 60 & \pm 38.9 & $(0-100)$ \\
\hline bodily pain & 74 & \pm 25.0 & $(22-100)$ \\
\hline general health & 80 & \pm 17.2 & $(42-100)$ \\
\hline vitality & 72 & \pm 19.2 & $(25-100)$ \\
\hline social functioning & 86 & \pm 17.8 & $(37-100)$ \\
\hline role functioning-emotional & 85 & \pm 27.4 & $(0-100)$ \\
\hline mental health & 76 & \pm 14.8 & $(48-100)$ \\
\hline
\end{tabular}

We found no statistical correlation between postoperative period and the studied variables, indicating that nine months was enough time to achieve the clinical outcomes.

\section{DISCUSSION}

Although two-stage bicruciate knee ligament reconstruction improved patients' knee stability and self-evaluation, $96 \%$ of patients did not achieve the pre-injury physical activity level. Injury period was inversely correlated with self-evaluated physical functioning, physical limitation, vitality, and mental health in the 36-item short form survey (SF-36). Bicruciate ligaments injuries are caused by high-energy traumas, so that associated lesions are commonly observed in these injuries. ${ }^{3}$ In our study, $72 \%$ of the cases owed to car and motorcycle accidents (Table 1).

The unsatisfactory and inconsistent clinical outcomes resulting from conservative treatments fostered the need for a surgical approach to treat bicruciate ligaments injuries. Yet, no consensus has been reached in the literature regarding the ideal moment for surgery. Whereas Shapiro and Freedman ${ }^{6}$ and Harner and Poehling ${ }^{7}$ recommend surgery between the second and third week post-injury, Chuang et al. ${ }^{8}$ believe that surgery should only be performed once the patient has restored the range of motion.

When evaluating joint mobility after surgical bicruciate reconstruction, Hayashi et al. ${ }^{9}$ observed $15 \%$ of the patients $(n=19)$ to present motion deficit; for Lo et al. ${ }^{10}$, such condition occurred in $27 \%$ of the cases ( $n=11)$ and for Hirschmann et al. ${ }^{11}$ in $38 \%(n=24)$. However, all of our study patients recovered knee range of motion after the two-stage surgery, suggesting that surgical trauma magnitude interferes in postoperative joint mobility.

Hirschmann et al. ${ }^{11}$ found $96 \%$ of patients in a series of acute and chronic cases to present knee postoperative stability. According to Ohkoshi et al. ${ }^{12}, 100 \%$ of the cases presented residual posterior drawer of less than $0.5 \mathrm{~cm}$. Spiridinov, Slinkard, and LaPrade ${ }^{13}$ reported significant improvement in subjective and objective evaluations and knee stability after endoscopic treatment of isolated and combined double-bundle posterior cruciate ligament (PCL) grade-III reconstruction.

Our results show an improvement in knee stability after bicruciate knee ligament reconstruction. Yet, $60 \%$ of the patients presented a residual posterior drawer of less than or equal to $0.5 \mathrm{~cm}$. We should also consider that our sample was heterogeneous, with $28 \%$ of patients presenting associated injuries such as a bone fracture or patellar tendon rupture.

Lo et al. ${ }^{10}$ evaluated 11 patients with bicruciate lesions and found $73 \%$ of them to present associated ligament injuries and $27 \%$ to present meniscal injuries. Subbiah et $a l .{ }^{14}$ reported associated ligament lesions in $73 \%$ of their study sample, Lustig et al. ${ }^{3}$ in $83,4 \%$ to $97 \%$, and Fanelli and Edson ${ }^{15}$ in $97 \%$ of 35 knee dislocation cases. Within our study sample, $48 \%$ had associated ligament lesions (Table 1), 16\% of which required additional surgical procedure. In turn, $44 \%$ of the cases had meniscal injuries.

Corroborating the results reported by Lo et al. ${ }^{10}$, our study recorded no postoperative complications.

In a study conducted with 9 patients with chronic bicruciate lesions, Schofer et al. ${ }^{16}$ reported a mean Lysholm score of 74 . Hirschmann et al. ${ }^{11}$ analyzed 17 cases of acute lesions and 7 cases of chronic injuries and registered a mean Lysholm score of $85(n=24)$. Lo et al. ${ }^{10}$ obtained a mean score of 88 for 11 chronic patients. In our study, an overall Lysholm score of 83 was classified as regular (Figure 4). A total of $64 \%$ of our sample presented chondral lesions, thus achieving poorer subjective Lysholm scores than patients without these injuries $(82.6 \pm 19.5$ and $85.0 \pm 11.5$, respectively). However, we verified no statistical difference between these groups $(p=0.609)$. Lustig, Lerayb, and Boisrenoulte ${ }^{3}$ reported $42 \%$ of their study sample to present chondral lesions.

Imprecise diagnoses, added to these patients' delayed referral to specialized services, contributed to chronic cases within our sample. 
Regarding pre-injury activity level, we found this complex lesion to significantly impair patients' quality of life. In a study conducted by Hirschmann et al. ${ }^{11}, 33 \%$ of the patients $(n=8)$ attained the pre-injury activity level, whereas for Lo et al. ${ }^{10}$ this number was $82 \%$ (9 out of 11). However, only one of the participants in our study attained the pre-injury activity level (4\%) (Tegner score activity =4) (Table 2). Considering isolated anterior cruciate ligament (ACL) reconstruction, Möller, Weidenhielm and Werner, ${ }^{17}$ and Nunez et al. ${ }^{18}$ recorded a mean SF-36 score higher than 70. Conversely, Sekiya et al. ${ }^{19}$ reported a mean score near 50 in isolated $P C L$ reconstruction, emphasizing that acute and subacute PCL injuries reached better scores than chronic injuries ( $p=0,036)$.

When analyzing bicruciate reconstruction, Schofer et al. ${ }^{16}$ and Hirschmann et al. ${ }^{20}$ observed a mean physical functioning SF-36 score ranging from 43 to 58 points, whereas in our study mean values were between 60 to 80 points (Table 3).

We also found preoperative injury period to be inversely correlated with the following items of the SF-36 questionnaire: physical functioning, physical limitation, vitality, and mental health. These findings indicate a negative effect of lesion duration on the postoperative outcomes.
Age, BMI, associated ligament lesions, posterior residual drawer, and postoperative follow-up duration were unrelated to postoperative outcomes.

This non-randomized retrospective study was conducted with a heterogenous sample of 25 patients with bicruciate chronic lesions submitted to a two-stage bicruciate knee ligament reconstruction using autograft and performed by the same surgeon. Considering this surgical procedure learning curve, which requires the harvesting of two or more autografts, as well as the surgical trauma and the time-lapse from trauma to surgery, a two-stage bicruciate knee ligament reconstruction could be deemed a realistic strategy.

\section{CONCLUSION}

Although two-stage bicruciate knee ligament reconstruction improved patients' knee stability and subjective evaluation, $96 \%$ of the study sample did not achieve the pre-injury physical activity level. Injury period was inversely correlated with self-evaluated physical functioning, physical limitation, vitality, and mental health in the SF-36 questionnaire.

AUTHORS' CONTRIBUTIONS: Each author contributed individually and significantly to the development of this article. SRP: surgery performance, data analysis, and writing, review, and intellectual concept of the article; MMI: surgery performance, data analysis, and writing of the article.

\section{REFERENCES}

1. Levy BA, Fanelli GC, Whelan DB, Stannard JP, MacDonald PA, Boyd JE, et al Controversies in the treatment of knee dislocations and multiligament reconstruction. J Am Acad Orthop Surg. 2009;(17):197-206.

2. Howells NR, Brunton LR, Robinson J, Porteus AJ, Eldridge JD, Murray JR Acute knee dislocation: an evidence based approach to the management of the multiligament injured knee. Injury. 2010;(42):1198-204.

3. Lustig S, Lerayb E, Boisrenoultc P. Dislocation and bicruciate lesions of the knee: Epidemiology and acute stage assessment in a prospective series. Orthop Traumatol Surg Res. 2009;(95):614-20.

4. Boisgard S, Versier G, Descamps S, Lustig S, Trojani C, Rosset P, et al. Bicruciate ligament lesions and dislocation of the knee: mechanisms and classification. Orthop Traumatol Surg Res. 2009;(95):627-31.

5. Piedade SR, Servien E, Lavoie F, Neyret P. Classification of knee laxities. In: Bonnin M, Amendola A, Bellemans J, MacDonald S, Ménétrey J. The Knee Joint. 1st ed. Paris: Springer-Verlag France; 2012. p. 85-93.

6. Shapiro MS, Freedman EL. Allograft reconstruction of the anterior and posterior cruciate ligaments after traumatic knee dislocation. Am J Sports Med. 1995;(23):580-7.

7. Harner CD, Poehling GG. Double bundle or double trouble? Arthroscopy 2004; (20):1013-4

8. Chuang TY, Ho WP, Hsieh PH, Yu SW, Chen YJ, Chen $\mathrm{CH}$. One-stage posterior cruciate ligament inlay reconstruction combining anterior cruciate ligament reconstruction following knee dislocation. Arthroscopy. 2006;(22):331-9.

9. Hayashi R, Nobuto KN, Kondo E, Anaguchi Y, Tohyama H, Yasuda K. Simultaneous anterior and posterior cruciate ligament reconstruction in chronic knee instabilities surgical concepts and clinical outcome. Knee Surg Sports Traumatol Arthrosc. 2008;(16):763-9.

10. Lo YP, Hsu KY, Chen LH, Wang CJ, Yeh WL, Chan YS, et al. Simultaneous arthroscopic reconstruction of the anterior and posterior cruciate ligament using hamstring and quadriceps tendon autografts. J Trauma. 2009;(3):780-8.

11. Hirschmann MT, Iranpour F, Muller W, Friederich NF. Surgical Treatment of Complex Bicruciate Knee Ligament Injuries in Elite Athletes: What Long-term Outcome Can We Expect? Am J Sports Med. 2010;(38):1103-9.
12. Ohkoshi Y, Nagasaki S, Shibata N, Yamamoto K, Hashimoto T, Yamane S Two-stage reconstruction with autografts for knee dislocations. Clin Orthop Relat Res. 2002;(398):169-75.

13. Spiridonov SI, Slinkard NJ, LaPrade RF. Isolated and combined grade-III posterior cruciate ligament tears treated with double-bundle reconstruction with use of endoscopically placed femoral tunnels and grafts: operative technique and clinical outcomes. J Bone Joint Surg Am. 2011;93(19):1773-80.

14. Subbiah M, Pandey V, Rao SK, Rao S. Staged arthroscopic reconstructive surgery for multiple ligament injuries of the knee. J Orthop Surg (Hong Kong). 2011;(3):297-302.

15. Fanelli GC, Edson CJ. Arthroscopically assisted combined anterior and posterior cruciate ligament reconstruction in the multiple ligament injured knee: 2 - to 10-year follow-up. Arthroscopy. 2002;(18):703-14.

16. Schofer MD, Peterlein CD, Fuchs-Winkelmann S, Kortmann HR. Arthroscopically-assisted combined anterior and posterior cruciate ligament reconstruction. Unfallchirurg. 2008;(111):703-10.

17. Möller E, Weidenhielm L, Werner S. Outcome and knee-related quality of life after anterior cruciate ligament reconstruction: a long-term follow-up. Knee Surg Sports Traumatol Arthrosc. 2009;(17):786-94

18. Núñez M, Sastre S, Núñez E, Lozano L, Nicodemo C, Segur JM. Health-related quality of life and direct costs in patients with anterior cruciate ligament injury: single-bundle versus double-bundle reconstruction in a low-demand Cohort-a randomized trial with 2 years of follow-up. Arthroscopy. 2012;(28):929-35

19. Sekiya JK, West RV, Ong BC, Irrgang JJ, Fu FH, Harner CD. Clinical outcomes after isolated arthroscopic single-bundle posterior cruciate ligament reconstruction. Arthroscopy. 2005;(21):1042-50.

20. Hirschmann MT, Zimmermann N, Rychen T, Candrian C, Hudetz D, Lorez LG, et al. Clinical and radiological outcomes after management of traumatic knee dislocation by open single stage complete reconstruction/repair. BMC Musculoskelet Disord. 2010;(11):102. 